\title{
Emilio Rabasa, narrador. La emergencia del pueblo en la representación narrativa del orden social de México
}

\author{
Emilio Rabasa, narrator. The Emergence of the People \\ in the Narrative Representation of Mexico's Social Order
}

\author{
LeONARdo Martínez Carrizales \\ Universidad Autónoma Metropolitana-Azcapotzalco \\ lemaca@correo.azc.uam.mx
}

RESUMEN: Este artículo estudia los parámetros de representación simbólica del orden social de México que el escritor y jurista Emilio Rabasa Estebanell construyó por medio de los códigos de la narrativa literaria. Esta preocupación desbordó por completo el dominio de las escrituras específicamente jurídicas, parlamentarias y periodísticas. En este sentido, en este trabajo se considera que la novela forma parte de una compleja atmósfera de escrituras, discursos, debates y representaciones simbólicas, fuera de la cual no puede interpretarse plenamente. En apoyo de la constitución legal (racional, universal, abstracta) del orden social de la nación mexicana, Emilio Rabasa acudió constantemente a los instrumentos y procedimientos intelectuales de la narratividad con el propósito de reducir al sentido propio de los instrumentos y recursos del orden letrado una realidad problemática, a veces caótica con respecto de las certezas y los ideales de la mentalidad liberal. En esa escritura se destaca el afán de describir, explicar y, en último término, comprender, desde el horizonte de enunciación del liberalismo, las poderosas tradiciones populares de México. En consecuencia, Rabasa llegó a plantear narrativamente la emergencia del pueblo como un actor social que cambiaría el orden simbólico de México establecido por los discursos de la modernidad política. Este proceso se estudia en La Guerra de Tres Años (1891).
Palabras clave:

Emilio Rabasa;

narrativa mexicana;

realismo literario;

novela corta;

liberalismo mexicano.

ABSTRACT: This article studies the keys of symbolic representation of the social order of Mexico that the writer and jurist Emilio Rabasa Estebanell constructed by means of the codes of literary narrative. This con- 
KEYWORDS: Emilio Rabasa; mexican narrative; literary realism; short novel; mexican liberalism. cern completely overflowed the domain of specifically legal, parliamentary, and journalistic writings. In this sense, in this work the novel is considered to be part of a complex atmosphere of writings, speeches, debates, and symbolic representations, beyond which it can not be fully interpreted. In support of the legal (rational, universal, abstract) constitution of the Mexican nation, Emilio Rabasa constantly referred to the intellectual instruments and procedures of narrativity in order to reduce a problematic reality - sometimes chaotic with respect to the liberal mentality's certainties and ideals - in the proper sense of the instruments and resources belonging to the literate order. This writing emphasizes an eagerness to describe, explain and, ultimately, understand, from the enunciation horizon of liberalism, the powerful popular traditions of Mexico. As a result, Rabasa came to narratively pose the emergence of the people as a social actor that would change Mexico's symbolic order, as it was established by the discourses of political modernity. This process is studied in La Guerra de Tres Años (1891).

\section{Planteamiento de la materia. La representación simbólica del orden social de México}

Este artículo tiene como interés dominante el estudio del clima intelectual que primaba hacia las postrimerías del siglo XIx en la comunidad de los expertos de la escritura y la lectura literarias cuya gestión cultural determinó, mediante los recursos de la narrativa, los parámetros de representación simbólica del orden social de México. Esta labor de representación literaria, a mi juicio, se encuadra y cobra pleno sentido en el horizonte de la preocupación más constante y notoria que las minorías letradas del país abrigaron a lo largo del siglo xix: la constitución jurídica y política de México de acuerdo con los universos conceptuales propios de la modernidad política, en la cual se destaca el liberalismo. ${ }^{1}$

\footnotetext{
${ }^{1}$ Propongo que compartamos, a propósito de la idea de "modernidad política", las explicaciones que al respecto propuso el historiador de la cultura política François-Xavier Guerra. De acuerdo con su punto de vista, en el amplio dominio de las sociedades
} 
Esta preocupación desborda por completo el dominio de las escrituras específicamente jurídicas, parlamentarias y periodísticas. En apoyo de este ingente esfuerzo de constitución legal (racional, universal, abstracta) del orden social de la nación mexicana, los peritos y los administradores del orden simbólico de la letra impresa acudieron constantemente a los instrumentos y procedimientos intelectuales de la narratividad con el propósito de reducir al sentido propio de los instrumentos y recursos del orden letrado una realidad problemática, a veces caótica con respecto de las certezas y los ideales de la mentalidad liberal. ${ }^{2}$ En ese "caos" se destaca el afán de

hispánicas hay una distinción clara entre actores políticos propiamente dichos y actores tradicionales. Los primeros corresponden al universo conceptual y de prácticas sociales propias de la modernidad política, ejercido por élites culturales autoconstituidas como grupos organizados para competir reguladamente por el control del poder político, diferenciado de otras actividades. Estos grupos se encuentran constituidos por individuos altamente diferenciados entre sí gracias a su educación formal y su pertenencia a círculos donde priman sociabilidades modernas como la escuela, el trabajo profesional, la concurrencia a todo tipo de "sociedades de conocimiento"... Los segundos corresponden a los cuerpos de la sociedad del Antiguo Régimen, cuya acción política no se diferencia de los acuerdos por medio de los cuales norman su convivencia habitual. A juicio del historiador francés, en esta esfera no hay actores políticos propiamente dichos, sino sujetos tradicionales que expresan y negocian sus intereses mediante su pertenencia a uno de los cuerpos de la sociedad tradicional, a cuyo seno sujetan todas sus actividades (Guerra 2012a).

${ }^{2}$ La noción de narratividad de que aquí se echa mano merece un comentario. Hayden White establece lo siguiente acerca de este recurso universal de formulación de conocimientos: "narrative is not merely a neutral discursive form that may or may not be used to represent real events in their aspect as developmental processes but rather entails ontological and epistemic choices with distinct ideological and even specifically political implications" (loc. 36-41). El relato constituido por los sujetos autorizados socialmente para codificar el conocimiento sobre la sociedad en su presente de enunciación consiste sobre todo en la articulación coherente e inteligible de una serie de sucesos en una secuencia capaz de suscitar una imagen verosímil del pasado. Esta serie organizada de acuerdo con las convenciones y valores de representación simbólica de la realidad cobra una función expositiva, tendiente a instilar en el lector la ilusión de que puede tener acceso efectivo a los acontecimientos; sin embargo, la serie organizada de sucesos en el relato puede obtener tal objetivo porque también ofrece una explicación. El relato es tanto un recurso de exposición como un instrumento de conocimiento. En estos aspectos expositivos y heurísticos radica la narratividad entendida como un metacódigo que rige una parte sustancial del funcionamiento del conocimiento humano. Este metacódigo se materializa en una fábula o universo narrativo acotado, concluido, suficiente por sí mismo y verosímil; el cual funciona como estructura de explicación del mundo y representación inteligible de un orden del mundo según las categorías de comprensión vigentes en un espacio histórico determinado. Sobre la no- 
describir, explicar y, en último término, "legalizar", por decirlo desde el punto de enunciación del liberalismo, las poderosas tradiciones populares de México. ${ }^{3}$ El diálogo conflictivo de la gran tradición liberal con las tradiciones populares emanadas del antiguo horizonte cultural mesoamericano es uno de los temas principales de la historia de la cultura literaria de México en el siglo XIX, y no solamente de la historia jurídica o política. ${ }^{4}$

La narración literaria es un campo institucional (géneros, prácticas letradas, modelos, temas, plataformas editoriales y periodísticas) que participó activamente en el diálogo sostenido por el liberalismo con las tradiciones populares; por virtud de esta participación, las narraciones de índole literaria se convirtieron en un elemento del debate cultural acerca de la identidad histórica del país y sus programas de viabilidad política. No menos importante fue el servicio que la narrativa literaria (entendida como parte de esta compleja atmósfera de escrituras, discursos, debates

ción de metacódigo, léase el parecer de Hayden White: "[...] far from being one code among many that a culture may utilize for endowing experience with meaning, narrative is a metacode, a human universal on the basis of which transcultural messages about the nature of a shared reality can be transmitted" (loc. 104-111).

${ }^{3}$ El fenómeno que se indica en las palabras que dan pie a esta nota es mucho más complejo que el relativo al miedo y el rechazo que en las élites modernas suscita la emergencia del pueblo movilizado por efecto de conflictos políticos de alcance estatal o nacional (Avechuco 2016).

${ }^{4}$ La tensión entre la gran tradición liberal de las sociedades occidentales y las "pequeñas" tradiciones locales y regionales es uno de los temas dominantes en el giro cultural de la historiografía política del siglo XIX, particularmente en México, dado su rico acervo de cultura popular de raíz agraria. Ya he consignado la deuda que he contraído acerca de la formulación de estos problemas con la influyente obra de François-Xavier Guerra y su círculo. En la redacción de las palabras que dan pie a esta nota también he tenido en cuenta la obra, no menos influyente para los estudios mexicanos, de Alan Knight, extremadamente sensible a la fuerza de las "pequeñas" tradiciones agrarias y serranas que terminarían por imponer en parte sus condiciones al legado del liberalismo mexicano (Knight 2010). El historiador inglés toma con cierta distancia la oposición entre la gran tradición liberal y las pequeñas tradiciones locales y regionales de Robert Redfield: "Como punto de partida de este análisis del proyecto revolucionario y su impacto, sugiero que todavía hay cierto valor heurístico en la distinción que hace Robert Redfield entre 'grandes' y 'pequeñas' tradiciones: la primera, ilustrada, escrita, nacional y 'moderna'; la segunda, iletrada, oral, local y 'tradicional'" (Knight 2013: loc. $4892-$ 4899). Esa oposición, hasta cierto punto, es operativa para el análisis de fenómenos que en este artículo se abordarán, sobre todo en lo que respecta a la identificación entre la primera con las ciudades y la segunda con las localidades (pueblos y comunidades agrarias con derechos de larga data). 
y representaciones) prestó a la determinación de la identidad socialmente construida de los sujetos letrados, y entre éstos, particularmente, los escritores literarios. Esta es la perspectiva de las páginas siguientes a propósito de Emilio Rabasa, autor de La Guerra de Tres Años, novela que se inscribe no sólo en la historia de la narrativa realista de México, sino también en el archivo de escrituras que hacia los últimos años del siglo xIx y los primeros del siguiente se propuso construir simbólicamente el orden social e histórico de México.

\section{El reconocimiento del comunalismo mexicano}

La narrativa literaria forma parte solidaria, junto con textos de diversa índole, del campo de la escritura en que una sociedad temporal y espacialmente circunstanciada lleva a cabo complejas transacciones simbólicas con el propósito de constituirse, en el sentido jurídico de esta voz, es decir, estabilizarse, sujetar a certezas el funcionamiento de la vida social, encauzar la agitación cotidiana de los seres humanos por medio de códigos homogéneos y universales. ${ }^{5}$ Como se sabe, la presencia de Emilio Rabasa en este proceso de constitución simbólica del orden social e histórico de México fue muy notoria gracias a su competencia como artífice del liberalismo en cuanto a la integración de sus expedientes en materia de derecho público.

De la base de la integración de tales expedientes modernos, abstractos y universales, emergió poco a poco, forjada en el taller de la imaginación narrativa de Rabasa, la comprensión de la fuerza y la vigencia de las tradi-

\footnotetext{
${ }^{5}$ Este párrafo se explica por sí mismo; por ejemplo, su contenido está próximo a la perspectiva teórica desarrollada por Roberto González Echevarría (véase bibliografía) y un rico campo de estudios que ha crecido alrededor de las relaciones entre literatura y derecho. Sin embargo, conviene insistir en un deslinde de estas páginas con respecto de las expectativas de lectura crítica generadas por la narratología. Quizá el deslinde más importante radique en una cierta identificación que me permito entre las instancias de autor y narrador, a los que indistintamente llego a caracterizar con el nombre del sujeto histórico Ilamado Emilio Rabasa. Me parece que esta licencia es dispensable en virtud de la convicción aquí establecida sobre la solidaridad de los textos literarios con otros tipos de texto en la atmósfera de la comunicación que prima en una sociedad históricamente determinada con el fin de desahogar sus necesidades de representación simbólica y debate cultural.
} 
ciones populares de México, fuentes de un orden alternativo, irreductible al orden liberal: el orden comunal del país. El ingreso del orden comunal en el sistema de representación literaria construido por nuestro autor abrió las puertas al entendimiento del giro populista que, tarde o temprano, se impondría en la constitución simbólica de México y, por ende, en su organización jurídica y política. ${ }^{6}$

Sin necesariamente proponérselo, Rabasa, por medio de sus narraciones literarias, contribuyó a la formación del clima intelectual que se configuraba lentamente hacia fines del siglo xIx y principios del siglo xx hasta volver inteligibles zonas emergentes de la realidad mexicana que no habían tenido derecho a la representación en los discursos vigentes en aquella época. Ese clima intelectual registra y estimula un punto de inflexión en la ciudad letrada sujeta al gobierno, durante un siglo, de las pautas liberales de comprensión y expresión del mundo. Hacia el periodo que nos atañe, hay un cambio de rumbo en los hábitos intelectuales de los funcionarios de la ciudad letrada de México que les permitió reconocer un problema fundamental en el orden constitucional del país: el comunalismo tradicional, esencialmente agrario, con un sentimiento enérgico de la localidad, irreductible a las operaciones modernizadoras de los instrumentos letrados del liberalismo. Emilio Rabasa, gracias a la representación narrativa de algunos aspectos del comunalismo tradicional de México $(v$. $g r$. los atributos del modelo del cacique, las lealtades corporativas, la fiesta, la violencia popular como recurso de expresión y transacción de los asuntos colectivos), dio pasos firmes hacia la explicación de este punto de inflexión que determinaría un cambio sustantivo no sólo en la tradición

\footnotetext{
${ }^{6}$ Me refiero al giro populista que caracterizó el entramado de ideas políticas y la estructura jurídica sancionados por las minorías culturales de la Revolución mexicana que adoptaron una parte de las demandas de los sectores populares movilizados a partir de 1913 con ocasión de la articulación no sólo bélica, sino también política, de diversos sectores populares en contra del régimen de facto de Victoriano Huerta. La Constitución de 1917 y las diferentes iniciativas de la reforma agraria son los ejemplos más tempranos del populismo revolucionario de México (Córdova 1972: 32-34; Córdova 1973: 188-261). La obra de Adolfo Gilly, La revolución interrumpida, 1972, ha sido escrita con base en el encomio de los sectores populares organizados bajo la autoridad de Francisco Villa y Emiliano Zapata. Una caracterización mucho más elaborada de estos sectores, distinguidos de acuerdo con las nociones de movilizaciones serranas y agrarias, corresponde a Alan Knight (2010: 981-996).
} 
liberal de México, sino también en los procedimientos de la narración realista.

El peso del derecho en la narrativa del autor no se agota en el ánimo de denunciar las insuficiencias de los personajes según las pautas dominantes en un Estado moderno y racionalizado, ni en la pedagogía que pudiera ejercer el hombre de letras ante sus coetáneos menos capacitados y poco dispuestos a conducir sus actos con base en la ley. Más allá de esto, las tradiciones intelectuales del derecho puestas en juego como consecuencia de la formulación e instrumentación de la cultura política moderna en el horizonte de los valores jurídicos del Antiguo Régimen sirven a Rabasa como lentes para observar los atributos, la conducta pública y los modos de relacionarse de los integrantes de la estructura social de México: los referentes del universo diegético.

Emilio Rabasa es muy sensible a este universo de fenómenos como lo demuestra la centralidad de un problema del derecho público en su obra: el control del Poder Ejecutivo central mediante contrapesos institucionales; la reducción del poder del dictador a una ley efectiva, respaldo (y límite) real (no utópico) de su fuerza. Este problema, en una escala menor (casi diría: en tono menor, el de la sátira) es el que se representa en su novela $L a$ Guerra de Tres Años: el jefe político sin el control de una ley efectiva. En lugar de ésta, en El Salado prima una ley utópica, burla de toda la comunidad y ocasión para la puesta en marcha de cualquier acto caprichoso.

\section{Pedagogía política en La Guerra de Tres Años}

Rabasa publicó por vez primera su novela corta, La Guerra de Tres Años, en El Universal. Las entregas de esta novela se desarrollaron entre el 22 de septiembre y el 3 de octubre de 1891, poco antes de que su autor se hiciera cargo de la gubernatura porfirista del estado de Chiapas, donde desarrolló, por encargo del presidente de la república, que así lo reconoció como parte de sus allegados, una gestión orientada al desarrollo material de la entidad, de acuerdo con los principios de la modernización autoritaria que primaban prósperamente en dicho periodo del Porfiriato (Hale 2011: 51-69). El análisis de la publicación de esta novela corta, así 
como también del resto de su obra narrativa, no puede quedar fuera de la plataforma institucional de gestión pública de nuestro hombre de letras.

El primer círculo de la comunidad intelectual en que se inscribió Emilio Rabasa se encontraba constituido por los participantes en el diario El Universal, dirigido por Rafael Reyes Spíndola, modernizador del periodismo mexicano en términos empresariales (Saborit: 18-32). En la oferta informativa de esas páginas cotidianas, se destacaba, por un lado, la discusión de la reforma constitucional del régimen político encabezado por Porfirio Díaz, y, por otro, la difusión, la propaganda y el análisis de las reformas modernizadoras de la economía impulsadas en el periodo. Emilio Rabasa participó de esta política informativa como editor, colaborador y posible socio del diario, además de amigo de Reyes Spíndola. Esta participación coincide con la primera estancia de Rabasa en la Ciudad de México, luego de haber Ilevado a cabo una trayectoria pública destacada en Chiapas, su estado natal, y Oaxaca, estado vecino adonde se extendían sus vínculos personales y sus relaciones de interés (Hale 2011: 35-69). Así que la presencia de Emilio Rabasa en El Universal representaba una ampliación de la órbita de sus actividades que lo colocaba en el gran escenario de la política nacional. La publicación de sus novelas es parte de las estrategias de esta promoción.

De acuerdo con el parecer del distinguido biógrafo de Emilio Rabasa, Charles Hale, La Guerra de Tres Años puede leerse plausiblemente como la justificación del régimen autoritario de Díaz dada su trayectoria hasta antes de su designación como gobernador. Antes que Hale, Daniel Cosío Villegas había planteado esta perspectiva al caracterizar a Rabasa como uno de los "enemigos" de la Constitución de 1857, y, por lo tanto, partidario de modificarla en aras del reconocimiento de un poder fuerte en el Ejecutivo (Cosío Villegas: 56-161). Según la lectura del historiador de las transformaciones del liberalismo mexicano, Emilio Rabasa habría querido satirizar el desorden social que imperaba en las localidades del territorio nacional, en condiciones de una evolución precaria de la comunidad política sometida a las tradiciones y la ignorancia, para concluir que sólo las directrices científicas impuestas dictatorialmente por las máximas autoridades de la nación eran capaces de fundar un gobierno efectivo (Hale 2011: 47-49). 
En verdad, la legibilidad del programa narrativo de Emilio Rabasa se encontraba afectada profundamente hacia los primeros años del decenio de los noventa del siglo xIx por un clima intelectual que se articulaba alrededor de los problemas relativos a la gobernabilidad eficiente dentro del orden constitucional del país promulgado en 1857. Entre tales problemas discutidos en México, como el propio Rabasa lo documentaría en su obra jurídica e histórica, desde el seno mismo del conflictivo congreso constituyente de 1856-1857 y la conciencia del primero de sus mandatarios al frente del poder Ejecutivo, Ignacio Comonfort, se destaca el relativo al freno constitucional de la autoridad del presidente de la república, cuya dictadura democrática (para echar mano del vocabulario de Emilio Rabasa informado en el dominio del constitucionalismo histórico) había fortalecido en exceso la índole y el alcance de sus atribuciones. Así, Rabasa participaba del planteamiento de una de las diversas modificaciones constitucionales que caracterizan la historia intelectual del Porfiriato, la referente a la inamovilidad de los magistrados de la Suprema Corte de Justicia, poder constitucional necesario para equilibrar el dominio del Ejecutivo $y$, en obediencia a una profunda matriz intelectual de la que Rabasa fue siempre partidario, retirar al Congreso facultades mediante la supresión de la elección democrática de los magistrados.

Me refiero a la proposición de modificación constitucional consistente en volver inamovibles a los ministros del tribunal supremo que los científicos, luego de haber constituido en 1892 la Unión Nacional Liberal, promovieron. "El Universal, el principal defensor en la prensa de los ministros inamovibles, Ilamó 'nuevos retrógrados' a los defensores doctrinarios de la Constitución, empeñados en frenar la evolución como si fueran organismos zoológicos que trataran de conservar sus rudimentarios miembros. La libertad, continuaba El Universal, no es nada 'metafísico', sino que se resuelve en 'hechos positivos'" (Hale 2011: 33).

Tal es la doctrina que Emilio Rabasa, quien había dispuesto de las páginas de El Universal para publicar su novela corta junto con sus artículos de crítica literaria, desarrollaría en sus dos obras de asunto jurídico más ambiciosas, particularmente La Constitución y la dictadura. Por ello, La Guerra de Tres Años, cuyo conflicto se plantea como resultado de la incompatibilidad de una comunidad humana sujeta a tradiciones profunda- 
mente arraigadas en materia religiosa y los principios abstractos del orden legal moderno, se vuelve plenamente legible en una atmósfera conceptual configurada con base en los problemas del derecho constitucional histórico en el México del siglo XIX, así como también la idea de la ley como un instrumento positivo de la organización de la sociedad, que debe alojarse en su conciencia como un objeto prestigioso y venerable, y en sus hábitos como una manera de ser.

De esta manera, La Guerra de Tres Años, igual que las siguientes novelas escritas por Rabasa, adopta el papel de un instrumento didáctico, recurso de formación de un ciudadano ejemplar, según la tradición liberal. En primera instancia, esto es lo que vuelve plenamente legible en su horizonte histórico una novela cuyo título llama la atención sobre la guerra que la facción liberal de la sociedad política mexicana libró entre 1858 y 1860 en defensa de los principios constitucionales y las leyes secundarias que reformaban el orden político del país con base en los principios del liberalismo y el republicanismo. Ese título obligaba al lector a hacerse cargo de la interpretación política e ideológica del relato del conflicto suscitado en un pueblo como consecuencia de una procesión religiosa que la grey católica saca del recinto eclesiástico y pasea por las calles de la localidad, en un abierto desafío a la autoridad civil. Ésta, centrada en la investidura del jefe político, responsable de guardar y hacer guardar la frontera entre los dominios civil y religioso que manda el laicismo del sistema político liberal, no atina a hacer valer su autoridad mediante los recursos que le ofrece la ley y se enreda cómicamente en los intereses menudos de los vecinos de la comunidad.

Así que, en primer lugar, La Guerra de Tres Años pone en juego la discusión de los principios no respetados que deberían hacer valer la separación entre la Iglesia y el Estado, baluarte doctrinal del republicanismo liberal de México y máximo recurso de la legitimación de la autoridad del núcleo dirigente de la sociedad mexicana desde la reforma constitucional del país en 1857 y, sobre todo, el triunfo definitivo de la facción liberal en la disputa por el control del aparato estatal, en 1867. En seguida, la novela se hace cargo de la discusión, cara a los intereses de los personajes más encumbrados intelectualmente en el núcleo dirigente del Porfiriato, acerca de las disposiciones morales e intelectuales de los mexicanos para 
encarnar la identidad del ciudadano de una república gobernada por el imperio abstracto, universal y racional de la ley.

Estas condiciones de legibilidad hacen de La Guerra de Tres Años algo más que una mera justificación del régimen autoritario de Porfirio Díaz; dichas condiciones la vuelven, en cambio, un documento literario que engrosa el expediente simbólico de vigilancia y control instruido por los peritos del discurso letrado al frente del proceso de racionalización estatal de una sociedad ajena a las pautas de esta reforma. Sin embargo de este estatuto, como ya lo he apuntado, hay en la historia narrada en La Guerra de Tres Años un excedente de sentido que las fronteras y principios liberales de la ciudad letrada no permitía procesar a la mentalidad del equipo de sus funcionarios.

\section{Excedente de sentido en la narrativa del liberalismo}

Emilio Rabasa Estebanell, narrador, jurista, funcionario público y representante popular en la esfera del Porfiriato, fue uno de los hombres de letras más distinguidos en el siglo xIX mexicano por virtud no sólo de su influyente obra como historiador y teórico del derecho constitucional, sino también de su concentrada y no menos influyente incursión en la narrativa realista. Rabasa perteneció al núcleo dirigente de México durante el prolongado gobierno del general Porfirio Díaz que consideró necesario fortalecer el poder del Estado como instancia máxima de organización y control de la sociedad. Para conseguir dicho fortalecimiento, nuestro hombre de letras confió en las tradiciones intelectuales de las que fue portador, sobre todo en cuanto se refiere al derecho constitucional. La perspectiva jurídica que Rabasa abrigó acerca del orden liberal no sólo alimentó, como era de esperarse, su obra de jurisperito, sino también $-y$ aquí reside mi perspectiva de estudio- de narrador.

Tanto en sus tareas como editor del diario El Universal como en sus empeños de novelista, Rabasa fue uno de los mediadores más notables entre la comunidad literaria de México y el realismo narrativo practicado por el grupo de los españoles Benito Pérez Galdós, Emilia Pardo Bazán, Pedro Antonio de Alarcón, Leopoldo Alas y Juan Valera (Galván Gaytán y Alfaro: 951). No obstante el prestigio de estos modelos, el escritor mexica- 
no imprimió a los códigos narrativos de los cuales se apropió expectativas mucho más ambiciosas en términos políticos. Con base en los instrumentos, los recursos y los modelos que la cultura literaria de su época puso a su alcance, Emilio Rabasa elaboró narraciones que explicaban la realidad social de México de acuerdo con las pautas de su mentalidad jurídica. La coincidencia del derecho y la narrativa literaria que ocurrió en la trayectoria de este intelectual porfiriano nos invita a pensar en un fenómeno característico de la identidad histórica de quienes, como Rabasa, son reconocidos como dirigentes de la comunidad nacional mediante su desempeño en cargos públicos donde se hacía valer su crédito como especialistas en alguna disciplina del discurso letrado.

El ejercicio narrativo de Rabasa se verificó en mitad de un itinerario que comprende el trabajo en tribunales y en diferentes instancias de la judicatura, así como también en puestos que nominalmente eran de elección popular en el México del periodo. El común denominador de esta trayectoria es el derecho, particularmente el diseño de la estructura y el funcionamiento del poder político sujeto al imperio de la ley. La narración literaria viene a ser, en la lógica de la mentalidad y la identidad socialmente reconocida de este actor histórico, un dispositivo cultural consistente en representar, comprender y explicar el orden social de México ante la luz de las estructuras abstractas del derecho. El programa narrativo de Rabasa, condensado en La Guerra de Tres Años, implicaba el juicio de la sociedad mexicana de los últimos lustros del siglo XIX ante el tribunal de los principios máximos de la mentalidad liberal propia de las minorías culturales y políticas del periodo, como lo son la educación del sujeto en una perspectiva racional del universo, el anticlericalismo consecuente de las obligaciones pedagógicas del Estado liberal, y la formación de un ciudadano obediente a los dictados de la ley.

La luz racional de la ley iluminó, a veces, un cuerpo social contrahecho, grotesco, materia del tratamiento satírico que caracterizó muchas páginas del narrador literario que fue Rabasa; otras veces, esa luz destacó en la conciencia letrada de las minorías culturales de México algunos aspectos de la estructura social del país de difícil comprensión para los sistemas conceptuales del liberalismo republicano y burgués, credo fundamental de los "mexicanos prominentes" que sujetaban bajo su direc- 
ción el destino de México en los años del régimen encabezado por Porfirio Díaz (Maria y Campos 1985). Cuando ocurre el primer caso señalado, las novelas de Rabasa satirizan a los personajes y las conductas que no se apegan a las expectativas de la modernidad política alimentada por el liberalismo; cuando ocurre el segundo caso, tales páginas, casi diría que a pesar del programa racional que las alienta, explican, describen y, en última instancia, legalizan en la conciencia letrada, conductas y personajes que desbordan por completo los límites del proyecto liberal, pero que caracterizan de un modo profundo la estructura histórica y social de México.

No obstante las aspiraciones de este programa narrativo a contribuir en la modificación de la sociedad mexicana de acuerdo con los principios fundamentales del liberalismo, la novela corta del narrador chiapaneco contiene los elementos de representación social propios para aproximarse al reconocimiento del orden populista de la sociedad mexicana por virtud de la concentrada atención que el narrador dispensó a las tradiciones constitutivas de la comunidad local, donde primaba una trama societaria que se teje por medio de lazos cordiales, ajenos a la racionalización modernizadora que el núcleo dirigente del liberalismo esperaba llevar a cabo sobre el orden social de México. Así, nuestro narrador contribuyó a dar una forma simbólica claramente inteligible para la comunidad intelectual de su época implicada en el debate sobre la organización política y social de México a una zona de la realidad que había sido marginada de la representación literaria dominante en el orden cultural del liberalismo.

La representación narrativa de la realidad mexicana llevada a cabo por Emilio Rabasa comprende un recurso didáctico, pues se propone la propagación de un ideal de ciudadanía contenido en el repositorio jurídico del liberalismo. ${ }^{7}$ Sin embargo, la pedagogía del ciudadano liberal y burgués en nuestro autor no agota sus intereses, pues hay un espectro de fenómenos inexplicables e irreductibles frente al universo del liberalismo que las narraciones de Rabasa reconocen y legalizan en el acervo de representaciones literarias del periodo; ese espectro corresponde al pueblo, un actor social emergente en el funcionamiento del sistema político del

\footnotetext{
${ }^{7}$ Consúltese específicamente Hayden White, "Droysen's Historik: Historical Writing as a Bourgeois Science" (White 1987: loc. 1713-2107).
} 
país. El pueblo es origen de un poder narrativo que singularizó a Rabasa en el panorama de las narraciones realistas de los últimos lustros del siglo XIX; poder cuya vigencia fue reconocida muchos años después, cuando la novela en que mejor se condensa este atributo, La Guerra de Tres Años, fue publicada nuevamente bajo la sanción de un entorno dominado por el replanteamiento populista del orden social y político de México. ${ }^{8}$

En cualquier caso, Emilio Rabasa, quien abandonó el ejercicio de la literatura luego de haber dado a conocer las cinco novelas que conocemos en su bibliografía, reservó para la narrativa histórica y el análisis constitucional el estudio del pueblo, sujeto colectivo que lo obligó a reconsiderar las pautas de su mentalidad liberal. En ese estudio se destaca una obra de 1912, La Constitución y la dictadura, en uno de cuyos lugares privilegiados el autor recuperó las intuiciones en materia popular que la narrativa literaria había prohijado en su entendimiento de México: las páginas donde culmina la narración del siglo XIx mexicano, ante el espectáculo de la caída del régimen de Porfirio Díaz.

De este modo, en primer lugar, la narrativa de Emilio Rabasa es legible en el contexto del aparato cultural del Estado liberal, especialmente en

\footnotetext{
${ }^{8} \mathrm{El}$ entorno al que me refiero en la frase que da pie a esta nota corresponde a los años treinta del siglo xx, dominados por el Cardenismo. En 1931 la novela corta escrita por Rabasa, La Guerra de Tres Años, se incorporó en el patrimonio narrativo de México legible de acuerdo con las pautas culturales del periodo en que la Editorial Cvltvra la dio a conocer en un formato editorial determinado por los valores de las artes populares, de orientación artesanal, desarrollados en el giro de la impresión de libros. La portadilla del volumen destaca las "maderas originales" de Isidro Ocampo que ilustran la novela y las capitulares de otro grabador dedicado a las artes editoriales, Ignacio Paco M., de quien no tengo noticia alguna hasta ahora. En cambio, sabemos que el autor de los 6 grabados que ilustran la segunda edición de La Guerra de Tres Años estudiaba con Antonio Díaz de León en el Taller de Artes del Libro, gracias a cuyo entrenamiento fue ilustrador de Cvltvra entre 1932 y 1939 . Ocampo fue integrante de la Liga de Escritores y Artistas Revolucionarios y miembro fundador del Taller de la Gráfica Popular. Las maderas que talló para ilustrar el libro de Rabasa se encuentran entre las primeras de su trayectoria, desarrolladas de acuerdo con los principios de compromiso del arte con las causas de los actores colectivos del país asociados al mundo del trabajo, particularmente trabajadores fabriles y agrarios. Aunque las maderas que nos incumben no desarrollan un discurso social explícito, su estética se condice naturalmente con la producción posterior de Ocampo y la de sus colegas más radicalizados. Así, esta marca editorial demuestra la incorporación de la novela corta de Rabasa en un clima cultural diferente de su contexto original.
} 
cuanto al cometido pedagógico que desde el punto de vista de la formación del ciudadano dicho aparato se había propuesto; y en segundo lugar, la formidable fuerza y el profundo arraigo de las tradiciones populares vigentes en las localidades y regiones de los "muchos Méxicos" irreductibles a la autoridad de un Estado político centralizador, homogeneizador y racionalizador, hizo que la sensibilidad y la inteligencia de Rabasa modificaran hasta cierto punto los recursos del realismo narrativo para prefigurar, varios años antes de que ésta se impusiera en el debate político, la primacía del pueblo irreductible a los ideales de la ciudadanía liberal como centro de gravedad de la nación mexicana. ${ }^{9}$

El reconocimiento de los "muchos Méxicos" ocurre gracias a la narrativa literaria; el artefacto narrativo funciona no sólo como representación de un referente que se considera real, verdadero, sino como explicación del excedente de sentido que resulta de un fenómeno irreductible o inexplicable de acuerdo con los parámetros de la racionalidad del lenguaje literario propio del liberalismo, es decir, el realismo.

\section{Un personaje: el jefe político}

El espacio social que sirve de escenario a la narración de Emilio Rabasa corresponde a las numerosas localidades donde se asentaba la mayor parte de la población del México independiente. Allí se encontraban los actores tradicionales del orden social del país hacia fines del siglo XIX, responsables de las negociaciones entre un archipiélago difícilmente articulado de comunidades de raíces históricas profundas y las entidades y los dispositivos de gobierno asentados en la capital del país. Entre esos actores tradicionales, Rabasa destaca al jefe político, un sujeto característico del Porfiriato en quien se depositaba la aplicación en las localidades de los intereses de gobierno dictados por la cabeza del Estado. A ese personaje se habían confiado las tareas de ampliación del radio de ejercicio de los

\footnotetext{
${ }^{9}$ La expresión "muchos Méxicos" proviene del título de un libro de una influyente historiadora de México y traductora de las letras españolas, parafraseado con regularidad por quienes se ocupan de la naturaleza diversa de la sociedad mexicana: L. B. Simpson. Muchos Méxicos. México: Fondo de Cultura Económica, 1977.
} 
principios de la ciudad letrada. Así que el jefe político era una figura estratégica para representar la conflictiva mediación entre la gran tradición liberal y las tradiciones locales y regionales contrarias a la primera (Guerra 1991: 122-125, 273-279).

El patrón de representación del jefe político que Emilio Rabasa utilizó en La Guerra de Tres Años es el mismo que había empleado en su extensa narración distribuida en cuatro volúmenes entre 1887 y 1888 ( La bola, La gran ciencia, El cuarto poder y Moneda falsa). Mateo Cabezudo en La bola y Santos Camacho en La Guerra de Tres Años responden a un estereotipo estratégico en el discurso de Rabasa. El estereotipo construye en la representación narrativa una figura real en el diseño de gobierno del Porfiriato, vínculo efectivo entre la comunidad local, de la cual emergía por su notoriedad en alguna virtud comunal y no por una carrera de honores en la administración de los asuntos públicos ni, mucho menos, el voto ciudadano, y la autoridad central de la república, tanto estatal como federal. El jefe político era una figura de autoridad a quien se encargaba el control efectivo de la comunidad local y no su representación política.

El origen de este cargo responde a los intereses de modernización centralizadora de la administración pública que data de las reformas borbónicas. Por ello, el jefe político siempre estuvo en tensión con respecto de la autonomía de los municipios, elegidos democráticamente por los habitantes de las localidades. La historia constitucional de México recupera esta figura de gobierno en virtud de las necesidades de gobernabilidad, organización electoral, administración fiscal, policía y pacificación en demarcaciones muy extensas, complejas y alejadas de los centros de poder. Así, el jefe político o prefecto se coloca entre los municipios y los gobiernos de los estados de la federación; en la mayor parte del territorio nacional, el nombramiento del jefe político dependía del gobernador, en menoscabo de la autonomía municipal, la independencia distrital y las tradiciones libertarias de los pueblos mestizos y comunidades indígenas. La ola de reformas practicadas en el texto de las constituciones de los estados a instancias de un gobierno central plenamente consolidado y dispuesto a emprender reformas modernizadoras no hicieron sino subrayar la condición del prefecto como agente de los intereses del Estado central, ajeno a la localidad. Tan es así, que la Revolución mexicana durante su 
primera fase, en su defensa de las libertades municipales, se alzó en contra de los jefes políticos, que para entonces ya habían perdido toda conexión con las comunidades en las cuales prestaban sus servicios (Guerra 1991: 122-125). El jefe político, en consecuencia, era una fuente de conflicto desde cualquier punto de vista para la instauración de la legalidad en las localidades constituidas por tradiciones ajenas, cuando no contrarias a la ciudad letrada de índole liberal, que Emilio Rabasa desarrolla eficazmente en sus narraciones.

El conflicto emana de la dificultad que el liberalismo homogeneizador y centralizador tenía para imponerse en regiones contrarias a sus intereses y sus tradiciones intelectuales, pero también de la incapacidad de sus agentes para representar dignamente, conscientemente, su código de valores $y$, consecuentemente, aplicarlo con honradez y eficiencia. De modo que el funcionario de la ciudad letrada que escribe La Guerra de Tres Años, por una parte, problematiza literariamente la renuencia de las localidades para someterse al orden del Estado liberal y, por otra, hace lo propio con respecto de la insuficiencia de dicha autoridad estatal para elegir a sus agentes y respaldarlos en sus obligaciones; insuficiencia ligada al poder y prestigio de las tradiciones antiliberales, populares y religiosas que efectivamente regían el orden de las localidades.

A este respecto, es destacable la caracterización del personaje correspondiente a Santos Camacho y sus atributos, siempre indicadores de faltas y errores con respecto del universo de la racionalidad letrada que se explican por su profunda índole popular. Este personaje es irreductible a todo sistema moderno; en él, la ley ni siquiera ha penetrado la piel de su sustancia popular, alimentada por inclinaciones que los detentadores del Estado liberal censuraban habitualmente como parte de sus tareas de transformación civilizadora y como insumo de su identidad socialmente construida.

El más notable en los procedimientos descriptivos que Emilio Rabasa desarrolla con el fin de cumplir con las funciones ideológicas de la caracterización del personaje radica en destacar la índole de su lenguaje y de su comportamiento en público. A este respecto, el personaje no ha sido reducido al orden de la civilización ni por haberse sometido a los códigos de control y sociabilidad modernos de la lengua ni por haber modificado 
las reacciones de su estado de naturaleza en beneficio de las normas de la cortesía. Los códigos y las normas, valiosos para la mentalidad de Emilio Rabasa, no han transformado la naturaleza del personaje correspondiente al jefe político; por ello permanece fuera del orden liberal y, al mismo tiempo, se convierte en una vía de acceso a la contemplación de la energía y la plenitud del orden popular.

Mateo Cabezudo y Santos Camacho, personajes homologables en el programa narrativo de Rabasa, pues el primero se proyecta sobre el segundo con mayor énfasis dada la concentración propia de la novela corta, son coléricos, agresivos, violentos y groseros; sus faltas continuas al orden y al decoro de la lengua constituyen el indicio que el narrador desarrolla continuamente para señalar en el personaje su autoridad elemental, no sujeta a ningún procedimiento institucional, ningún trámite, ninguna formalidad. Con respecto del régimen social apegado a derecho, el jefe político representado por Emilio Rabasa se encuentra en el estado de naturaleza, marginal a todo convenio jurídico.

En esta representación se problematiza la primacía de los lazos tradicionales del jefe político, profundamente arraigado en el orden popular, del cual procede su incapacidad para cumplir adecuadamente con su papel de funcionario de la legalidad del Estado. Esta identidad no sólo sirve como vehículo para conducir la conciencia del lector hacia temas centrales del aparato cultural del liberalismo como el anticlericalismo y la educación racional del ciudadano, sino también, y aquí radica la independencia del criterio del autor, para señalar el origen extralegal de la autoridad encarnada por el jefe político y su contribución a la gobernabilidad dictatorial de una sociedad que sólo finge la obediencia a la ley y se sustrae del todo a su imperio.

Ni Mateo Cabezudo ni, mucho menos, Santos Camacho pueden ser autoridades civilizadoras de sus comunidades respectivas. No lo pueden ser porque ni su mentalidad ni su conducta populares han sido transformadas por los códigos del sujeto educado en el orden liberal (la ley, el lenguaje, la cortesía del ciudadano democrático); y tampoco pueden serlo porque su autoridad se asienta en un fundamento legal discutible, próximo a las transacciones con los enemigos del liberalismo y propicio al gobierno dictatorial, es decir, extralegal. 


\section{La ley de los gallos y las verbenas}

La acción de Santos Camacho en La Guerra de Tres Años obedece a sus pasiones más elementales, de acuerdo con un mecanismo narrativo de índole irónica, figura dominante del programa narrativo en su totalidad. Quien debiera estar Ilamado a la aplicación prudente y sabia de las disposiciones reglamentarias en materia de las manifestaciones públicas del culto católico, según el marco jurídico de las Leyes de Reforma, aludidas en el título de esta novela corta, en realidad sólo aplica su autoridad con respecto de una procesión en honor del patrono del pueblo de El Salado instigado por la inquina de dos mujeres que han sido sus barraganas en distintas épocas; la rivalidad sexual de las mujeres cobra su imperio en la voluntad del sujeto rústico, veleidoso y sensual, incapaz de llevar a cabo una medida administrativa coherente apegada a derecho, pero rápido en aplicar su capricho en el gobierno de su comunidad.

Emilio Rabasa subraya la índole popular de las disposiciones del jefe político, coherentes con el origen extralegal de su cargo, por medio de la narración de uno de los atributos más destacados de este sujeto y el orden comunal en el que se inserta: su frenesí por las peleas de gallos. A este respecto, el autor incurre en una censura que ha sido habitual en la gestión de las minorías letradas a lo largo del siglo XIX, representantes y dirigentes del orden moderno: el vilipendio de la sensualidad del pueblo, verificada en entretenimientos sangrientos que se celebran habitualmente en el marco de otros actos de sociabilidad populares, igualmente censurados, como las fiestas patronales y las procesiones religiosas.

La descripción del palenque constituye una de las escenas más interesantes de la novela en virtud de la viva, detenida y prolija descripción realista del narrador a propósito de la fiesta popular que se lleva a cabo en las proximidades del ruedo. El furor que suscita en Santos Camacho el espectáculo sangriento de las peleas de gallos, y el prestigio social que el personaje atribuye al ganador de esta clase de torneos, colma los intereses del jefe político. La narración de este acontecimiento también conduce a la comprensión de la función que desempeña como mecanismo de negociaciones entre localidades vecinas del orden popular que gobierna la mayor parte de la comunidad nacional. La censura moderna del 
liberal Emilio Rabasa no será tanta que cierre sus ojos ante la energía del entretenimiento popular y su importancia en el orden y la estabilidad de la región. ${ }^{10}$ Así que la censura de los entretenimientos sangrientos no basta para explicar la delectación con que el narrador describe, por ejemplo, la justa de los gallos. Allí, como en todos los pasajes que consignan la fiesta popular, el narrador cede ante la densidad, la espectacularidad y la fuerza de las tradiciones populares.

La lucha tuvo peripecias: el giro volaba y la navaja hendía el aire a rápido golpe sin tocar al adversario, que parecía esperar, agazapándose, a que su enemigo se fatigara. El giro se detuvo al cabo, picando la tierra, mientras alrededor de su cresta encendida formaba con las plumas del cuello un cerco de oro; parecía provocar y calcular a la vez. Repentinamente se lanzó sobre su enemigo, abriendo poco las alas, casi sin volar; echó atrás todo el cuerpo y sus dos espolones se cerraron sobre el riochiqueño con terrible fuerza.

Un grito unánime se levantó del palenque: el colorado estaba mortalmente herido. El giro acometió otra vez, y luego otra y otras muchas, ciego, sin cálculo, como vencedor novel e imprudente, mientras el colorado retrocedía tambaleándose hasta pegarse a la valla. Ya iba a caer, ya los saladenses se disponían a invadir la plaza cuando el riochiqueño, haciendo un esfuerzo supremo, saltó sobre el giro y le asestó un golpe. El herido dio un paso atrás y cayó muerto; el colorado pudo llegar junto al vencido, se echó sobre él y murió sin una convulsión, tranquilo, quieto.

El vocerío aguardentoso y rabioso estalló en el patio con algazara infernal, sin que pudiera distinguirse una voz de la otra; la gente se apiñó dentro de la valla, alzando mil disputas que amenazaban concluir por las vías de hecho $[\ldots]$ (Rabasa 1891g: 2).

Por otro lado, el narrador pone de manifiesto, mediante recursos irónicos que se hacen posibles desde las nociones liberales constitutivas de su

\footnotetext{
${ }^{10}$ Recuérdese que en la narración, el prefecto participa con singular frenesí en la pelea de gallos porque allí mide sus fuerzas con las de su contraparte en un pueblo vecino. El torneo sangriento sublima las rivalidades entre comunidades cercanas. "El giro parecía como el legítimo representante del Salado contra Río Chico, y la lid fue asunto de amor propio, casi de amor patrio" (Rabasa 1891g: 2). Se diría que el autor comprende con clarividencia lo que un estudioso moderno de la estructura social de México en el siglo xIx a propósito de la índole de la política en sociedades de una fuerte raíz tradicional. La política en estas comarcas no es una actividad diferenciada con respecto de los papeles desempeñados por los actores sociales que integran la comunidad, sino que se identifica con su conducta habitual (cfr. Guerra 2012a: 214-243, 438-450).
} 
horizonte de comprensión y expresión, los mecanismos tradicionales del gobierno encabezado por el jefe político. La ironía destaca el contraste entre el orden teórico del liberalismo mexicano y el orden tradicional vigente, efectivo, en una comunidad "premoderna" en lo relativo a valores políticos. La jefatura política personificada cuidadosamente por el narrador expone el eclecticismo del entramado social en el cual se inserta con naturalidad: autoridad pública que ejerce sus facultades de gobierno extraconstitucionalmente, con base en convenios establecidos por costumbre con los diferentes cuerpos que constituyen la comunidad política: la Iglesia, el comercio en pequeño, el gran comercio, los propietarios de fincas rurales, los agricultores, los asalariados de diversa índole; cuerpos representados en la narración por medio de figuras estereotipadas que cumplen eficientemente con el propósito de esquematizar el sistema de fuerzas políticas y económicas que impera en la localidad. La autoridad pública asentada en el escenario de estas negociaciones locales, como lo pone de manifiesto el final de la novela, en última instancia se atiene al poder político de la ciudad capital de la nación, también proclive a dictar medidas extralegales.

El mecanismo narrativo de La Guerra de Tres Años se asienta sobre el contraste de dos órdenes irreductibles entre sí que el autor dispone para su representación narrativa de acuerdo con su mentalidad moderna. En este sentido, el orden social narrado se caracteriza por un error, una falta, un defecto sustantivo que se comprende a partir de una base de relaciones tradicionales irredimible por el régimen teórico del liberalismo. De allí se alimenta la sátira que caracteriza retóricamente los recursos de representación del jefe político y de la comunidad que gobierna. Santos Camacho, eje del orden ecléctico de su comunidad según las pautas de la mentalidad liberal de quien narra, es construido como una figura cómica que divierte por los defectos de su estado de naturaleza que se acusan ante una situación que exigiría de él discernimiento y criterio informado: la regulación de una procesión católica que sale del recinto religioso para deambular por las calles del pueblo sin el permiso de la autoridad, como lo exige el estado de derecho.

El ridículo de este personaje incapacitado intelectual y moralmente para comprender el problema político y de gobierno que se implica en el reto de la grey a la autoridad política para hacer manifestación pública de su fe se 
desarrolla en la novela corta mediante la reducción de la índole de la materia a un conflicto de celos femeninos en torno del jefe político, despojado en la narración de toda dignidad aparejada a su cargo de gobierno. Todas sus acciones se convierten así en defectos cómicos que subrayan su estado de naturaleza, iletrado, ágrafo, y ahondan la distancia que lo separa de los sistemas conceptuales que priman en el orden constitucional del liberalismo.

Uno de los personajes en el cual el narrador ha depositado la representación de la conciencia liberal es un comerciante en pequeño, adversario de los mayoristas coludidos con las autoridades de todos los niveles de gobierno para asegurar la prosperidad de sus negocios. Este personaje, liberal puro, juarista y, por lo tanto, partidario de la sustancia doctrinal de la carta de 1857, se refiere así al jefe político cuando tiene oportunidad de juzgar su conducta a propósito del control de la procesión religiosa que desfila por las calles del pueblo sin el permiso de la autoridad: “—iQué liberal va a ser ese bruto!" (Rabasa 1891f: 2.) En efecto, bruto ante la conciencia liberal porque su estado de naturaleza lo priva del discernimiento propio de la dignidad de la autoridad pública y lo arroja a la sensualidad desenfrenada de los gallos y el alcohol.

Santos Camacho es indiferente ante los preparativos de la procesión y sólo atina a suspenderla violentamente en el palenque donde se juega su fortuna a los gallos, espacio que sustituye a las oficinas de gobierno. Esta escena y la que sigue en el orden de la narración sirven al autor para describir con amplitud, cuidado y aun interés, costumbres populares de diversa índole: el palenque de gallos y apuestas, la verbena popular con motivo de la fiesta patronal del pueblo y la procesión. Estas últimas concentran a la comunidad en la plaza pública, al margen de las instancias del gobierno constitucional. Esta intrusión del pueblo en el régimen letrado de la ciudad expresa la reducción de las Leyes de Reforma a la nada en el ánimo público, entregado completamente al imperio de las tradiciones que efectivamente organizan a la comunidad y hacen posible la gestión de sus intereses, sin cuidado por los dispositivos de la escritura y la promulgación de la ley que de ésta emana.

El discurso de Emilio Rabasa a favor del orden social de la letra y de la reducción de la vida al sistema de la ley considera al pueblo volcado a las calles en verbenas y procesiones religiosas, interesado en suertes 
de caballo y luchas de gallos, como ignorante. De este pueblo denso y multitudinario proceden los intereses menudos que hacen avanzar la narración de La Guerra de Tres Años, eficazmente concentrados en el pasaje correspondiente al enfrentamiento irreconciliable del partido de la religiosidad tradicional con el de los anticlericales. La voz popular es el vehículo del recrudecimiento de esta disputa que sólo se resolverá con el arrebato ridículo del jefe político enardecido por el alcohol, el palenque y el consejo de la voz que llega hasta sus oídos luego de una serie de rumores y chismes intercambiados y aderezados de un bando a otro sin medida ni control ni registro letrado. El pueblo impone el dictamen de su voz, sucedáneo de cualquier instrumento escrito de la administración pública. Esta irreductibilidad de la voz popular, poderosa e incontenible, amenazante para el orden letrado, muestra el convencimiento del organizador del universo diegético acerca de la ignorancia radical del pueblo, de su incapacidad para el discernimiento del orden político, de su separación esencial con respecto de los ciudadanos capaces de hacerse cargo de la cuota de soberanía que les corresponde en la investidura de la autoridad pública. Por esta línea de razonamiento de matriz jurídica, el pueblo de los gallos y las verbenas queda al margen de la ciudad letrada y es, en verdad, una amenaza al orden civil.

\section{La influencia popular convertida en voluntad soberana}

En cuanto a la consideración del pueblo en la mentalidad liberal de Emilio Rabasa, leamos esta caracterización de índole política, procedente de una obra histórica y jurídica posterior en poco más de dos decenios a La Guerra de Tres Años, La Constitución y la dictadura. Sólo en esas páginas, luego de una trayectoria parlamentaria de primer nivel en que pudo reflexionar acerca de la estructura jurídica sobre la cual se asienta la gobernabilidad del país, y ante la inminencia del fin del régimen de Porfirio Díaz, Rabasa enunció su desasosiego ante las vociferaciones de la masa social.

Lo malo es que la palabra pueblo tiene en los idiomas occidentales tres connotaciones que la ignorancia, y muchas veces el simple descuido, confunden; la 
de masa social en conjunto; la de suma de individuos capaces de ejercitar los derechos políticos, y la de pueblo bajo, por contraposición a la parte culta y acomodada de la sociedad. De esta confusión han nacido todas las teorías falsas y todas las vociferaciones perversas de que se alimenta la demagogia (Rabasa 1912: 11-12).

Tanto la "masa social" como "el pueblo bajo" amenazan a la conciencia letrada por ser fuente alimentadora de la demagogia, estado social indiferente al respeto de la ley como conductora y moderadora de sociedades. "[...] las masas ignorantes no gobiernan en ninguna parte y precisamente el pecado del jacobinismo democrático consiste en haberlas contado como factor de gobierno" (11). Sólo "la parte de la sociedad que tiene conciencia de la vida nacional" merece el nombre de pueblo digno de intervenir en la vida política y de tener influencia en el destino del país (11); el pueblo que puede comprender el principio abstracto de la soberanía popular y la función institucional que se desprende de éste: la asamblea de los representantes del pueblo soberano, la investidura popular de la autoridad legal, la distribución y el equilibrio de los poderes populares... En suma, el pueblo aprobado por Emilio Rabasa no se corresponde con el que representa en su novela corta, indiferente a estas ficciones de la mentalidad letrada, tanto, que puede terminar por destruirlas. Así que al desprecio del pueblo espeso imperante en la conciencia letrada del autor, se suma el miedo ante el poder ciego de esta fuerza colectiva, su pronta disposición para sumarse a la bola en obediencia de cualquier enemigo de los poderes públicos legalmente constituidos o de cualquier dictador inescrupuloso.

La ley es la única medida para preservar a la sociedad constituida de semejantes peligros según el legislador de la ciudad letrada. Cuando su prestigio se abate y se hace acreedora de la burla o de la indiferencia de todos, y consecuentemente deja de rectificar las inclinaciones de la "masa social" o el "pueblo bajo", entonces las amenazas de éstos se tornan todavía más inquietantes para el escritor/legislador pues, amparándose en el fetiche de una ley vacía, desprovista de imperio sobre la sociedad que estaba Ilamada a honrarla y obedecerla, la multitud puede entregarse sin límite ni freno a sus caprichos. Tal es "la bola" que se narra en el primer libro de la extensa narración de Emilio Rabasa; tal es el ridículo al que el 
principio de la separación de la Iglesia y el Estado queda reducido bajo el imperio efectivo de la voz popular atizada por un pleito de concubinas que doblegan a la autoridad pública. El peligro queda planteado en las narraciones antipopulares de Rabasa, aunque no se desarrolle dramáticamente y sus proporciones queden reducidas tanto en La bola como en La Guerra de Tres Años a la sátira.

Sin embargo de esta caracterización satírica del imperio del pueblo entregado a sus tradiciones sobre una autoridad incapaz de honrar el mandato de la letra de la ley, el narrador es particularmente cuidadoso en la descripción del espectáculo humano por medio del cual se revelan los lazos y los valores que efectivamente gobiernan a la comunidad; gracias a esa descripción se comprende el papel desempeñado por cada uno de los cuerpos de la comunidad en la representación colectiva, fuente de su identidad. A este respecto se destaca la composición de lugar necesaria para el desarrollo del discurso realista en el inicio de La Guerra de Tres Años, pasaje simétrico con respecto del inicio de La bola, aunque en la escala correspondiente a una narración breve. Se trata de la representación de la fiesta que pone en escena a los integrantes de la comunidad organizados en cuerpos tradicionales. En La bola los cohetes del ayuntamiento y los tambores se mezclan con las campanas dobladas por el sacristán de la parroquia para producir, "más que el regocijo público", "el comienzo frenético de una asonada tremenda" que es el inicio de las festividades del 16 de septiembre por medio de las cuales la narración presenta al sujeto colectivo de la comunidad (Rabasa 2004: 3-8); otrosí ocurre en La Guerra de Tres Años cuando rompen los repiques de "la campana grande, la cuarteada y la esquila" (Rabasa 1891a: 2).

Desde la primera página de la narración, el autor muestra su interés y conocimiento calificado del orden popular de las localidades de México, base efectiva de la república, tal y como su conocimiento excepcional de la historia política del país se lo indica. Así, las descripciones más disfrutables de este costumbrista conocedor de los veneros políticos que circulan debajo de los hábitos pintorescos para la conciencia letrada corresponden a diversas modalidades de fiestas populares en las cuales se disuelve la trama. Tal procedimiento sólo es posible por el interés genuino de este escritor/legislador en los sectores populares, marginales con respecto del 
orden letrado de la ley. Interés y temor propio de un especialista en las instituciones letradas que durante casi un siglo han sido incapaces de reducir al orden de la ciudad liberal al "pueblo bajo", la "masa social", por recordar el vocabulario de Rabasa. Interés y temor en el hombre de letras que ha determinado por obra de sus procedimientos narrativos el ingreso del pueblo en el orden de los discursos letrados que aspiran a representar la estructura social de México. La representación que Emilio Rabasa ha hecho con inteligencia y sensibilidad de este ámbito de la sociedad mexicana es tan prolija y eficaz que ha gestado figuras de larga vigencia en la cultura literaria de México, como la del jefe político, matriz conceptual y representacional del cacique, el caudillo o cabecilla de los movimientos populares del país en el siglo xx.

Ahora bien, la gravedad de los temores que el pueblo infunde en la conciencia letrada debido al influjo que éste ejerce en los asuntos públicos fue desarrollada por Emilio Rabasa en los capítulos dedicados a la narración de la historia de México que constituyen la primera parte de su estudio La Constitución y la dictadura, desarrollo ulterior de la materia que aquí abordamos, planteada en su novela corta. En ese libro publicado en 1912 y redactado en el horizonte caracterizado por los primeros asedios populares a la ciudad letrada, Rabasa desarrolló la explicación de su interés y temor con respecto de la base popular de la sociedad mexicana. En tal explicación imprime todas sus capacidades cultivadas en el dominio de lo que él mismo llama ciencia política, específicamente en las materias del derecho público y la historia constitucional.

En consecuencia, Rabasa desarrolla en el territorio de la cultura letrada más refinada su inclinación por incorporar teóricamente, en el orden letrado de la ciudad, el contingente del pueblo extraño a la mentalidad liberal. De acuerdo con mi perspectiva, no se trata de un gesto de control o dominio simbólico, sino de un reconocimiento, un intento por hacer del conocimiento ilustrado una vez más una zona de la realidad que, habiendo permanecido irreductible al orden de los discursos liberales, los ha trastocado, ha desestabilizado su funcionamiento, los ha desnaturalizado y, por tanto, exige su replanteamiento.

El horizonte de formulación textual correspondiente a 1912, año de publicación de La Constitución y la dictadura, no permite a Emilio Rabasa 
incidir una vez más en las pautas irónicas de sus narraciones, ajenas a la gravedad que a la sazón había cobrado el problema. En el marco conceptual de una obra dedicada a examinar las reformas necesarias en el texto de la Constitución de 1857 con el objeto de hacerla efectiva en la conducción y educación del pueblo, Rabasa consigna la centralidad amenazante del pueblo en el orden constitucional de México de la siguiente manera: el orden constitucional emanado de la Constitución de 1857 y de las Leyes de Reforma, que de acuerdo con su análisis histórico y jurídico ha sido causa de la dictadura por el apartamiento que todo gobernante en México ha practicado con respecto de sus disposiciones reglamentarias, goza, paradójicamente, de un prestigio indiscutible. Un prestigio tal que no hay asonada posterior a 1857 que no se haya pronunciado a favor de la carta magna, "[...] de suerte que cada movimiento subversivo ha tenido la virtud singular de extender más y más en los pueblos la convicción de que la Constitución es sagrada, de que ella sostiene los derechos que violan todos los gobiernos malos, y que por ella es lícito rebelarse contra las autoridades constituidas para cambiarlas por otras que respetarán y obedecerán la Ley suprema" (Rabasa 1912: 110).

Tal es la paradoja ridiculizada en La bola; tal es la máscara grotesca adoptada por una celosa concubina que atiza el fuego de la separación de la Iglesia y el Estado con el único fin de imponerse a su rival. Sin embargo, la situación de 1912 ya no deja lugar a esta solución narrativa y a la modalidad de la sátira. La fe ciega en la Constitución de 1857, escribe Rabasa, ya no es patrimonio de "las capas sociales que ocupan tanto las clases directoras como las que pueden eslabonarlas con los inferiores" (111). Medio siglo de reformas sugeridas y de cambios de facto practicados en la letra de la Constitución impide a los funcionarios de la ciudad letrada practicar la admiración fanática de la ley. Entonces, ¿en quién recae el peligro de mantener este fingimiento que daría pábulo a insurrecciones tan espectaculares y peligrosas que los recursos narrativos del autor ya no pueden representar? Cierto, "en las masas incultas que forman un credo de sus sentimientos, y que forman sus sentimientos en los discursos patrióticos de los oradores de fiesta cívica" (111). Esta es la última ironía que se permite el escritor/legislador ante la magnitud que ha cobrado el sujeto popular en su conciencia ilustrada, capacitada como pocas para 
darse cuenta de la índole del problema que aquél promueve en el orden constitucional de México.

Todos los gobiernos están llamados a obedecer en época más o menos cercana a la influencia de los pueblos, y cada día la palabra pueblo se aproximará más a la significación de multitud. La influencia popular, que casi no cuenta por ahora, crecerá por ley ineludible y acabará por transformarse en voluntad soberana, y como para tal avance de la multitud no se necesita que ésta tenga la idea del deber y de la responsabilidad, sino sólo que alcance la conciencia de su fuerza, su advenimiento será la catástrofe para la nación si en las masas se han alimentado los prejuicios que las extravían y los fanatismos que las enconan (111).

El advenimiento de la conciencia de la fuerza de los sectores populares transformada en voluntad soberana constituye el límite conceptual del discurso del narrador/legislador. Sobrepasada esta frontera sólo se vislumbra la catástrofe de la ciudad letrada. Por ello, la conclusión lógica del autor se reduce a reformas constitucionales que hagan posible el fortalecimiento efectivo de las instituciones públicas y disuadan a cualquier gobernante de adoptar indefinidamente medidas dictatoriales. Tales reformas, como sabemos, se concentran en el diseño de gobierno y de las esferas de la administración pública. La utopía letrada de este narrador/legislador se olvida de la índole tradicional de un pueblo que ha representado tan eficazmente, y por ello supone que podría ser contenido en paz en las demarcaciones establecidas por la letra de la ley, por los dispositivos reformados del orden de la ciudad letrada.

\section{Conclusión. La teoría del populismo mexicano}

A pesar de este umbral que la conciencia letrada de Emilio Rabasa no podía rebasar en 1912, las manifestaciones del descontento popular ni le eran desconocidas ni despertaban su rechazo absoluto. En los sistemas conceptuales que habían educado a este escritor/legislador la inquietud popular puede ser fuente de legitimidad de un régimen preconstitucional o paraconstitucional que se opone a los agravios infligidos por un mal 
gobernante que se ha desembarazado de todo control legal, o que reúne a la comunidad política para salvaguardar su organización al margen de los desequilibrios de un orden de gobierno insostenible, fuente de discordias continuas. En el primer caso, Rabasa piensa en la índole populista del discurso de la Revolución de Ayutla, dique de un dictador desenfrenado, promesa de destrucción de un orden de privilegios y anuncio de reformas sociales (Rabasa 1912: 39, 123 y ss.). Así, la narración histórica de Rabasa sostiene que la fuente de legitimidad de la Reforma es la violencia. En el segundo caso, el autor se refiere a la rebelión armada de Porfirio Díaz, violencia popular cuyo triunfo lo libera del aparato legal promulgado por el constitucionalismo de 1857.

La revolución que depuso a Lerdo de Tejada y elevó a la presidencia al general don Porfirio Díaz, dio a éste una posición más libre que la que asumió su antecesor al subir al poder; no recogió, como él, una herencia que debiera respetar, ni una tradición con que fuera necesario transigir; llevado al gobierno por la violencia revolucionaria, no tenía con el pasado compromiso alguno, sino que sentía el apremio de la lógica para destruirlo. Llegaba, sí, al poder rodeado de héroes, que tenían derechos superiores a los que da la tradición en la sucesión legal y pacífica [...] (151).

La violencia popular triunfante tiene fueros con respecto de un orden constitucional que aquella, por el hecho de haber prosperado, ha declarado caduco. El pueblo movilizado, entonces, tiene plenos derechos para modificar el orden constitucional en el sentido de sus intereses con el objeto de legalizar (es decir, sancionar por medio de los dispositivos de la letra) su legitimidad armada. Emilio Rabasa reconoce plenamente en 1912 que el "sentimiento populista [...] es la estela de las revoluciones victoriosas" (106). Dicha estela comenzaría a convertirse en letra dos años más tarde, abriendo así un ciclo de textos y discursos consumado en el orden populista de la Revolución mexicana, fuente de su régimen jurídico tanto como del régimen de sus narraciones. ${ }^{11}$

\footnotetext{
${ }^{11}$ En 1914, luego de la caída del gobierno de Victoriano Huerta, se hará claro en la mente de los políticos profesionales educados en la esfera del liberalismo que los sectores populares de la coalición constitucionalista impedirían definitivamente el regreso a las posiciones liberales del maderismo. Tal es el estado de cosas que determina el
} 


\section{Bibliografía}

Avechuco Cabrera, Daniel. "Los intelectuales ante la violencia de la Revolución Mexicana", en La Colmena. Revista de la Universidad Autónoma del Estado de México, 92 (octubre-diciembre 2016): 25-37.

Cabrera, Luis. "México y los mexicanos", en Stanley R. Ross (coord.). ¿Ha muerto la Revolución Mexicana? Causas, desarrollo y crisis. Vol. 1. Trad. Héctor David Torres. México: Secretaría de Educación Pública, 1972. 77-88 (SEP Setentas, 21).

Córdova, Arnaldo. La formación del poder político en México. México: Ediciones Era, 1972.

Córdova, Arnaldo. La ideología de la Revolución Mexicana. La formación del nuevo régimen. México: Ediciones Era, 1973.

Cosío Villegas, Daniel. La Constitución de 1857 y sus críticos. $4^{\mathrm{a}}$ ed. México: Fondo de Cultura Económica, 1998.

Galván Gaytán, Columba y Norma Alfaro. "Emilio Rabasa", en María Rosa Palazón Mayoral (coord.). Fronteras diluidas entre historia y literatura. México. Siglo XIX. México: Universidad Nacional Autónoma de México / Universidad Autónoma Metropolitana / Fundación para las Letras Mexicanas, 2012. 945968. CD.

Gilly, Adolfo. La revolución interrumpida. México: Ediciones Era, 1994.

GONZÁlez ECheVArRía, Roberto. Mito y archivo. Una teoría de la narrativa latinoamericana. $2^{a}$ ed. Trad. Virginia Aguirre Muñoz. México: Fondo de Cultura Económica, 2011.

Guerra, Françols-Xavier. México: del Antiguo Régimen a la Revolución. T. I. $2^{\mathrm{a}}$ ed. Trad. Sergio Fernández Bravo. México: Fondo de Cultura Económica, 1991.

Guerra, François-Xavier. "Hacia una nueva historia política: actores sociales y actores políticos", en Figuras de la modernidad. Hispanoamérica siglos XIXxx. Comp. Annick Lemperière y Georges Lomne. Trad. Juan Carlos Garava-

Pacto de Torreón y, sobre todo, la composición y el mandato de la fallida Convención de Aguascalientes (Córdova 1973: 188-261; Knight 2010: 981-996). Entre los políticos profesionales más próximos a Venustiano Carranza, se destaca Luis Cabrera. En 1916, este precursor de la reforma agraria, no sólo reconoció, como Rabasa, la legitimidad de la violencia revolucionaria, sino que intentó una explicación teórica del proceso por medio del cual la violencia popular adquiría, luego de destruir un régimen político injusto y desconocer el entramado jurídico en que se asentaba, el derecho de transformarse en gobierno dictatorial y, después, en nuevo régimen (Cabrera: 85-87). La constitucionalidad del régimen revolucionario no emanaba del voto de los ciudadanos, sino de la legitimidad de la violencia popular transformada en políticas públicas de redención social que ampliaban la base de la ciudadanía, más allá de las pautas establecidas por el liberalismo. Esta "explicación científica" (la expresión es de Cabrera) de la Revolución mexicana no sólo alimenta las escrituras políticas y jurídicas que articulan racionalmente el nuevo régimen, sino que da pie a la escritura literaria, específicamente narrativa, que pretende hacer legible dicho régimen (Valadés y Leal: 13-86). 
glia y Nicolás Suescún. Bogotá: Universidad Externado de Colombia / Taurus, 2012a, location 142-497.

GuerRA, FrançoIs-XaVIer. "El pueblo soberano: fundamento y lógica de una ficción (países hispánicos del siglo XIX)", en Figuras de la modernidad. Hispanoamérica siglos XIX-XX. Comp. Annick Lemperière y Georges Lomne. Trad. Juan Carlos Garavaglia y Nicolás Suescún. Bogotá: Universidad Externado de Colombia / Taurus, 2012b, location 498-1230.

Hale, Charles A. "La tradición del derecho continental europeo y el constitucionalismo en el México del siglo xx: el legado de Emilio Rabasa", en Historia Mexicana. Ciudad de México. XLVIII: 1 (julio-septiembre 1998): 97-125.

Hale, Charles A. La transformación del liberalismo en México a fines del siglo xix. Trad. Purificación Jiménez. México: Fondo de Cultura Económica, 2002.

Hale, Charles A. Emilio Rabasa y la supervivencia del liberalismo porfiriano. El hombre, su carrera y sus ideas. 1856-1930. Trad. Antonio Saborit. México: Fondo de Cultura Económica, 2011.

KNight, Alan. La Revolución Mexicana. Del Porfiriato al nuevo régimen constitucional. Trad. Luis Cortés Bargalló. México: Fondo de Cultura Económica, 2010.

KNIGHT, AlAN. "Proyecto revolucionario, pueblo recalcitrante: México, 19101940", en Repensar la Revolución Mexicana. Vol. I. Trad. Silvia Cuesy y Sandra Luna. México: El Colegio de México, 2013, location 4813-6185.

MARIA y CAMPOS, AlFonso DE. "Porfirianos prominentes: orígenes y años de juventud de ocho integrantes del grupo de los científicos, 1846-1876", en Historia Mexicana. Ciudad de México. XXXIV: 4 (abril-junio 1985): 610-661.

Otero Zamacona, Mario Alejandro. "La influencia del constitucionalismo anglosajón en el pensamiento de Emilio Rabasa", en Apuntes Electorales. Revista del Instituto Electoral del Estado de México. Nueva Época. XII: 48 (enero-junio 2013): 145-149.

RABASA, EMILIO. La Constitución y la dictadura. Estudio sobre la organización política de México. México: Tip. de Revista de Revistas, 1912.

RABASA, Emilio. La Guerra de Tres Años. México: Editorial Cvltvra, 1931.

RABASA, EMILIO. El cuarto poder y Moneda falsa. $7^{a}$ ed. México: Editorial Porrúa, 1998.

RABASA, EmilıO. La bola y La gran ciencia. 15a ed. México: Editorial Porrúa, 2004.

SABORIT, ANTONIO. El Mundo llustrado de Rafael Reyes Spíndola. México: Centro de Estudios de Historia de México Condumex, 2003.

Sancho Polo [Rabasa, Emilio]. "La Guerra de Tres Años. I", en El Universal. México (22 de septiembre de 1891a): 2 .

Sancho Polo [Rabasa, Emilio]. "La Guerra de Tres Años. II", en El Universal. México (23 de septiembre de 1891b): 2.

Sancho Polo [RAbasa, Emilio]. "La Guerra de Tres Años. III", en El Universal. México (24 de septiembre de 1891c): 2.

Sancho Polo [Rabasa, Emillo]. "La Guerra de Tres Años. IV", en El Universal. México (25 de septiembre de 1891d): 2.

Sancho Polo [RabaSA, Emilio]. "La Guerra de Tres Años. V", en El Universal. México (26 de septiembre de 1891e): 2 . 
Sancho Polo [Rabasa, Emilio]. "La Guerra de Tres Años. VI", en El Universal. México (27 de septiembre de 1891f): 2.

Sancho Polo [RABasa, Emilio]. "La Guerra de Tres Años. VII", en El Universal. México ([28] de septiembre de 1891g): 2.

Sancho Polo [Rabasa, Emilio]. "La Guerra de Tres Años. VIII", en El Universal. México (30 de septiembre de 1891h): 2.

Sancho Polo [Rabasa, Emilio]. "La Guerra de Tres Años. IX", en El Universal. México (1 de octubre de 1891i): 2.

Sancho Polo [Rabasa, Emilio]. "La Guerra de Tres Años. X", en El Universal. MéxiCo (2 de octubre de 1891j): 2.

Sancho Polo [Rabasa, Emilio]. "La Guerra de Tres Años. XI", en El Universal. México (3 de octubre de 1891k): 1.

VALAdÉs, Edmundo y LuIS LeAL. La Revolución y las letras. Dos estudios sobre la novela y el cuento de la Revolución Mexicana. México: Consejo Nacional para la Cultura y las Artes, 1990 (Tercera Serie. Lecturas Mexicanas, 14).

WhITE, HAYDEN. The Content of the Form. Narrative Discourse and Historical Representation. Baltimore: The Johns Hopkins University Press, 1987.

\section{LeONARDo Martínez Carrizales}

Maestro en Letras Mexicanas y doctor en Letras (Facultad de Filosofía y Letras, UNAM). Actualmente, es profesorinvestigador titular $\mathrm{C}$ adscrito al Departamento de Humanidades de la Universidad Autónoma Metropolitana, plantel Azcapotzalco.

En esa institución se desempeña como integrante del cuerpo docente del Posgrado en Historiografía y de la Maestría en Literatura Mexicana Contemporánea. Su libro más reciente es Tribunos letrados. Aproximaciones al orden de la cultura letrada en el México del siglo XIX (UAM-A, 2017). Es integrante del Sistema Nacional de Investigadores. También ha sido profesor de la Facultad de Ciencias Políticas y Sociales de la Universidad Nacional Autónoma de México entre los años de 1992 y 2008.

Es autor, entre otros libros, de La sal de los enfermos. Caída y convalecencia de Alfonso Reyes. París 1913-1914 (2001); Alfonso Reyes-Enrique González Martínez, El tiempo de los patriarcas. Epistolario 1913-1914 [estudio, edición 
y notas] (2002); El recurso de la tradición. Jaime Torres Bodet ante Rubén Darío y el modernismo (2006). También ha sido editor de dos libros colectivos: Espacio. Presencia y representación (2009) y El orden cultural de la Revolución Mexicana. Sujetos, representaciones, discursos y universos conceptuales (2010).

Entre sus líneas de investigación se destacan, además de las minorías letradas del México independiente, la crítica y la historia literarias, la historia de la retórica en México, Alfonso Reyes, Pedro Henríquez Ureña, Emilio Rabasa y la Revista Mexicana de Literatura. 